\title{
Rural Landscape as Heritage: Reasons for and Implications of Principles Concerning Rural Landscapes as Heritage ICOMOS-IFLA 2017
}

\author{
Lionella Scazzosi \\ Department of Architecture, Built Environment and Construction Engineering, Politecnico di Milano, Milan, Italy \\ Email: lionella.scazzosi@polimi.it
}

\begin{abstract}
In 2011, the ICOMOS-IFLA International Scientific Committee on Cultural Landscapes (ISCCL) began the World Rural Landscapes Initiative (WRLI) project to develop a complete and systematic approach to cultural heritage for rural areas. Rural landscapes need further study in terms of methodology, operation and internationally recognised documents: protection and promotion, knowledge, methodology and management at international, national and local levels. The goals of the WRLI were: a principles text containing theoretical, methodological and operational criteria; a website; a glossary; an atlas of rural landscapes; and a general bibliography. The first goal has been achieved: Principles Concerning Rural Landscapes as Heritage was adopted as a doctrinal text by ICOMOS (2017). This paper presents the main cultural premises and contents of the Principles text: (I) the theoretical concepts of the 'Rural Landscape' and 'Rural Landscape as Heritage'; and (II) 'Action criteria' which guide the development of policies for rural landscapes as heritage and resources: knowledge, protection, sustainable management, communication and transmission of physical places and associated heritage values. This paper covers: the importance of time in policy strategy; the (false) contradiction of conservation and innovation and the concept of 'appropriate' transformation; the role of stakeholders; value recognition; knowledge; information; communication and public reception.
\end{abstract}

KEYWORDS rural landscapes, heritage, principles text, theoretical definitions, methodological issues, action criteria

Received June 26, 2018; accepted August 14, 2018.

\section{Preamble}

In 2011, the ICOMOS-IFLA International Scientific Committee on Cultural Landscapes (ISCCL) began a cultural project, the World Rural Landscapes Initiative (WRLI), with the goal of a complete and systematic approach to the question of cultural heritage for rural areas. This subject has not been sufficiently studied, either in terms of methodology and operation or official internationally recognised documents. This is a very different story from other sectors of 'tangible' and 'intangible' cultural heritage (the expression used to articulate the description of heritage in international forums, e.g., at UNESCO level).

\section{Extending the Concept of Heritage to Landscapes}

The process of extending the concept of heritage over the $20^{\text {th }}$ century has shifted attention from a single object, considered of exceptional value but isolated from its context, to the study of less precious and more common heritage and to the cataloging of many types of heritage. The content of the most important international scientific documents clearly shows this pathway, from the Athens Charter in 1931 to the Venice Charter in 1964, to the Krakow Charter in 2000 (Le Goff 1978; Choay 1992; Scazzosi 2002; Lennon 2012; Goetcheus and Mitchell 2014).

The field had long included churches, palaces, villas, castles and abbeys, but it also came to encompass historic town centres, industrial archaeology, rural architecture and peasant culture. During the 1970s, experts became aware of the value of historic gardens and plantings, as well as the products of Modernism and the sub-layers of 'material culture', testifying to the life of human beings. Another step on this path conceived the entire landscape 
as an object, rich with traces of natural and human history. In this approach, the landscape is the result of centuries of small daily actions of construction and transformation carried out by agricultural workers, punctuated by single greater events-drainage works and works by large land-holders-and the construction of new urban settlements. In the recent ICOMOS Charter on the Conservation and Restoration of Cultural Heritage (ICOMOS, 2000) the landscape, understood as cultural heritage, has taken its place as an item of interest for the first time.

Connected to this cultural journey, is the evolution of legislation concerning heritage protection, which, above all in Western countries over the first decades of the $20^{\text {th }}$ century, concerns not only 'historical monuments' (Jokilehto 1999), but also so-called 'natural beauties'. This is a concept that unifies the cultural vision (aesthetic and more) of nature with the scientific one and has become one of the roots of the contemporary understanding of landscape (Luginbühl 2012). In the past, the word 'landscape' was used to describe a purely artistic representation of places by painters.

UNESCO is credited with considering rural landscapes as heritage from the 1980s onwards. In 1992, UNESCO introduced the concept of landscapes at a global level, in substitute for the more generic 'site' which was a feature of World Heritage Convention (UNESCO 1972). Rural Landscape was a category of interest for the Convention (Art. 1 and 2) but had become insufficient as attention shifted and grew towards a more precise understanding of the meanings of 'landscape', 'nature' and 'environment'ideas which had been previously confused or, paradoxically, seen as separate concepts (Leach 1980; D’Angelo 2001).

It is interesting to review the debate leading to the 1992 document, which has been little studied (Droste, Plachter, Rössler 1995; Fowler 2003a, 2003b; UNESCO 2003a; Cameron and Rössler 2013; Gfeller 2013), because this scientific elaboration started as a result of the difficulty in conceiving rural landscapes seen through separate visions of nature and culture ('natural sites' and 'cultural sites'), with stringent operational consequences in evaluation of candidates for the World Heritage List.

At the beginning of the 1980s, there was growing demand for inclusion in the World Heritage List, leading to difficulty, in a scientific and operational mode, in clearly separating 'natural sites' from 'cultural sites' as foreseen by the World Heritage Convention. This was particularly acute in sites whose value was predominantly natural, but were historically used or built by man (cases like Meteora, in Greece; Capri, in Italy; the Lake District, in England)
(Cameron and Rössler 2013, 60-64). On top of this, especially during the phases of candidacy, theoretical and methodological research was taking place on certain geographical landscapes (for example, 'terraced landscapes', and 'vineyard landscapes').

In 1984, the notion of 'rural landscapes' was introduced to the Committee meeting in Buenos Aires by the French delegation: 'Historically, since Neolithic times, in Europe at any rate, man has greatly transformed the land to cultivate it, to make it habitable. In transforming the land, he has modified the ecosystem ... he has created a new land that often presents outstanding characteristics, for example the rice terraces of Java or the Philippines, which respond to the spirit of the Convention.' (Cameron and Rössler 2013, 61)

An expert task-force from ICOMOS, IUCN and the International Federation of Landscape Architects (IFLA) was set up and worked over the years 1985/1986 to create the underlying documentation that would include 'rural landscapes' in the Committee Guidelines for the World Heritage List, formulating definitions and evaluation criteria. In 1987, at the World Heritage Committee, the concept of 'mixed sites', was coined which possessed 'both cultural and natural attributes', with rural landscapes being part of this. Then, the definition changed again: the concept of 'cultural landscapes' was used by the Committee for the Lake District in England (in 1987 and 1989), an emblematic case leading to numerous requests for the site to be included on the World Heritage List, which was finally granted in 2017. The term 'cultural landscapes' is 'a new term that curiously replaced the term 'rural landscapes' without explanation' (Cameron and Rössler 2013, 66).

In 1992, a definition was given to 'cultural landscapes' so they became part of the heritage category in the Guidelines, with three sub-categories: 'continuing landscapes', 'designed landscapes' and 'associative landscapes'. Since then, within the cultural landscapes 'continuing landscapes' category, the sub-category 'ongoing landscapes' has included rural landscapes even if the latter were not explicitly mentioned in the definition. Methodological, historical and practical on-site research can identify whether any other forms of 'ongoing landscapes' can be recognised in addition to rural landscapes (such as some mining landscapes).

The second half of the $20^{\text {th }}$ century saw profound transformations in the concept of landscapes (Luginbühl 2012). This was rooted in the European Landscape Convention (ELC) (Council of Europe 2000), endorsed by the Council of Europe, a document which has become a reference 
point for other continents, so much so that it is now possible for non-European countries to adhere to its principles. This introduced innovative concepts into the debate and the general operation, with landscapes included as both a physical object and a cultural perception; the right of all people to enjoy quality of life in any place, avoiding strategies that would create 'protected islands' of exceptional cultural or natural significance; the need for widespread participation in place management, considering the vast areas in question, across all stakeholders; and the identity value of landscape, in addition to being a physical and cultural resource, i.e., landscape is to be considered from the heritage point of view too.

The term used now is simply 'landscape', without further adjectives (such as cultural or natural or historic). This concept eliminates separation between nature and culture (landscape is 'the result of the action and interaction of natural and/or human factors'-Art.1) because a landscape is always physical and cultural. The nature-culture separation has been a part of Western culture over the $20^{\text {th }}$ century (D’Angelo 2001; Olwig 2002; Scazzosi 1999; Scazzosi 2002; Donadieu, Küster, Milani 2008; Taylor and Francis 2014) and is partly linked to the growth of independent environmental and ecological scientific approaches and protection policies (Deléage 1991). This has become a subject for discussion and international debate (Beresford, Brown and Mitchell 2005), both for furthering international visibility of Oriental approaches to landscape (Taylor and Lennon 2012; Han 2012; Taylor 2012) and as general approach to heritage (ICOMOS Australia 2013). There are also important convergences between the World Heritage Centre (WHC) and the European Landscape Convention (ELC) (Scazzosi 2003a, 2004). Historical articulation from Western cultures on the concept of landscape-both in the scientific approaches and in national legislation-is not widely known at the world level and could be useful to improve the current international debate.

\section{Toward a Systematic Approach to Concepts and Tools}

The international research and documents coming out of UNESCO in the 1990s demonstrated the need for a systematic vision on three aspects: 'classification' ('The first challenge...is to find an approach to the classification of typology of such landscapes...'); 'evaluation' ('The second... is to develop meaningful guidance for comparative evaluation of the quality of such landscapes...'); and 'management' ('The third challenge is perhaps the most daunting of all. Because the essence of this type of cultural landscape is its dependence on a living culture, the management of such landscapes has to be through the community, rather than of the landscape as such') (UNESCO 1995, 445). This touches on the question of criteria and the stakeholders active in the protection of a site whose end-users change it through continuous and capillary transformations.

As long ago as 1985, expert working groups had identified all rural landscapes as sites of interest, not only those of exceptional quality: 'Continuing landscapes... are very widespread: all agrarian landscapes can be considered in that light' (UNESCO 1995, 445); only through widespread knowledge can sites of particular value be correctly identified (' $[$ it is the] basis from selecting from such a potentially vast field') (UNESCO 1995, 445). Therefore, widespread study is necessary across the world's regions ('extensive consultation and comparative study on a regional basis are essential') (Cleere 1995, 55).

The WRLI develops three crucial questions posed by debate in the 1980s which have certain key aspects. The first is scientific: finding a solution to the lack of methodology concerning the knowledge and management of the heritage aspect of rural landscapes, making the solution, in general terms, a shared, usable tool for all countries. This approach can have relevant consequences on operations over the current historical moment in which such a necessity is growing quickly.

The perceived wisdom at the time was to start from an empirical basis, featuring large scale rural landscape categories then under study and often under consideration for inclusion on the list: 'landscapes associated with rice cultivation'; 'landscapes associated with pastoralist groups' (for example, the Saami population in the Northern Scandinavia); 'landscapes associated with non-agricultural societies' (for example, hunter-gatherer societies such as the Aboriginals of Australia); settlement landscapes 'vernacular settlements' (as in Hungary and Slovakia) which are 'surrounded by land-holding patterns ... still in use' (Cleere 1995, 55); 'and some other landscapes which have been fashioned by humanity (e.g. managed by fire regimes)' (UNESCO 1995, 445).

More recently, other projects, directed toward the creation of a global rural landscape protection inventory have taken place. The FAO with Globally Important Agricultural Heritage Systems (GIAHS) declared that in 'traditional agricultural knowledge systems' tied to rural locations and communities' attention is primarily dedicated to maintaining site-specific technical traditions. The Convention for the Safeguarding of the Intangible Cultural Heritage 
(UNESCO 2003) is sometimes used as a tool to indirectly safeguard the physical aspect of rural landscapes, as it recognises the importance of specific agricultural technical traditions and includes them on the World Heritage List (WHL, this is the case of citrus fruit cultivation on the island of Pantelleria, Italy). In addition, there are catalogues of national projects, such as the Italian catalogue, which is promoted by the Ministry for Agricultural. Food and Forestry Policies (Agnoletti 2013). Each of these tools is intended to identify and protect exceptional sites in a kind of 'oasis of happiness' way.

Today, the question is looked at more directly: the cultural landscapes on the WHL are numerous and comparative, so systematic study is possible. Certain rural landscape study programs are at an advanced phase. Systematic knowledge projects for all rural landscapes as heritage which exist in different regions across the globe can be collected, compared and improved. For example, in Europe, some international research has begun to apply a systematic knowledge of heritage to all rural landscapes (Meeus, Wijermans and Vroom 1990; Fairclough and Møller P.G. 2008; Pungetti and Kruse 2010).

The second reason, closely linked to the first, concerns heritage protection and management in the development of rural sites. Rural territory is considered an economic, environmental, social and productive resource. Awareness also of its cultural relevance has grown over recent years, becoming a key expression of a population's identity. This awareness is specifically driven (and maybe accelerated) by the fact that rural landscapes in many parts of the world are undergoing radical transformations due to the growth of urban areas and the progressive abandonment of the countryside, intensive and industrial farming methods and the loss of local rural knowledge and traditions. It must be said that the process of recognising new categories of historical heritage and their protection has always had, among its drivers, the perception of a progressive separation from the idea of the asset representing contemporary values and the idea that its transformation will lead to a complete loss of historical foundation and remnants.

While the sense of appreciation towards the historical and cultural values of rural landscapes among many populations in the world is increasing, there is a grave lack of criteria and strategies in place to maintain such sites unless they are of exceptional quality. It is also true that many projects, differing in scale and focus, publicly or privately managed, deal with rural landscapes as heritage-some of these succeed, others dramatically fail. This happens for a variety of reasons, including: lack of multi-disciplinary and multi-stakeholder approaches which would lead to policy able to overcome sectorial disagreements or the start-stop problems often experienced where many players are involved (experts, academics, public administration, local councils, local communities, farmers, land owners, citizens); and the lack of scientific background to define typology, definition and reading of a site, to support local, regional, international or even global knowledge and policies. The difficulty in taking decisions continues to grow, because landscapes are in continuous evolution thanks to their links to farming practices and farmers' ways of life. Clearly, such a situation requires research and experience concerning the double-sided coin of transformation and conservation, although these aspects are not necessarily contradictory. There is also difficulty in evaluating traces of heritage in the present day, the concept of authenticity and acceptance of elements of differing epochs, all now historical in significance. 'The criterion of authenticity here needs liberal interpretation, rejecting only discordant elements from an alien culture (for example, garish billboards advertising western consumer goods in an oriental agricultural landscape).' (Cleere 1995, 58)

A key role was played by the ICOMOS-IFLA Charter on Historic Gardens, Florence 1982 (UNESCO 1982), which not only focused attention on open spaces but built areas too. It introduced the theoretical and methodological question of how to protect heritage values when the assets in question are in rapid transformation, being made of natural materials leading to specific problems that other types of historical heritage, like buildings of mineral origin (made up of e.g., brick and stones), do not seem to encounter. It is worth bearing in mind that the reference for heritage protection criteria was the Venice Charter (ICOMOS 1964), and that over the 1970s, a heated debate took place (for example, in Italy) concerning the opposition of theoretical and operational conservation considering the importance of all historical phases of places, or reconstruction meaning returning the site to one specific period (Brandi 1963; Jokilehto 1999). A debate took place for historic gardens between one position considering only the permanence of the shape related to a specific period as a value, and another considering the values of its tangible materials as document of the past and as symbolic features, as is a very old tree (Scazzosi 1993, 27-83). Western cultural positions on historic gardens and landscapes were and are actually more varied than expected by non-experts and they are useful for going deeper into the methodological issues needed by the 'landscape as heritage' approach. 
From these needs came the WRLI whose aim was to form the foundation of a common thread concerning protection and promotion, knowledge methodology and management of rural landscapes at differing levels (international, national and local). The project was aimed at all bodies involved in such processes to encourage the exchange of experience and knowledge and strengthen awareness of the value of rural landscapes based on each one's particularities, traditions and sustainable usage.

The goals of the WRLI are to create: a principles text containing theoretical, methodological and operational criteria; a website ${ }^{1}$ to involve experts and stakeholders; a glossary; an atlas of rural landscapes; and a general bibliography. Research is carried out by academics, researchers and professionals from around the world, members of the ISCCL, but also by international associations, public bodies, universities, local groups and volunteers. Inside ISCCL, a multi-disciplinary group was set up. The WRLI has been developed according to traditional university scientific studies and is effective because multiple cultures and rural knowledge from across continents are leveraged leading to exchange, debate and sharing of the differing cultural approaches. The first goal has been achieved: a draft of a principles document was subject to an intense period of preparation by the ISCCL working group and passed through national and international committees in the ICOMOS association as well as other international cultural institutions (IUCN, FAO-GIAHS), individual academics and international cultural associations. The Principles Concerning Rural Landscapes as Heritage were approved by the IFLA in October 2017 and adopted as a doctrinal text by the ICOMOS General Assembly in Delhi in December 2017 (ICOMOS 2017a). Its predecessor was the ICOMOS-IFLA ISCCL Milano Declaration 2014.

The Principles' preamble encompasses the document's raison d'etre. The document sums up the value and peculiarities of rural landscapes as a physical and cultural resource. It underlines just how widespread such conditions are ('one of the most common types' of landscapes and its features of 'continuing cultural landscapes', according to the UNESCO definition Guidelines): 'Rural landscapes are a vital component of the heritage of humanity. They are also one of the most common types of continuing cultural landscapes. There is a great diversity of rural landscapes around the world that represent cultures and cultural traditions. They provide multiple economic and social benefits, multifunctionality, cultural support and ecosystem services for human societies' (ICOMOS 2017a). The following is the document's fundamental focus: 'This document encourages deep reflection and offers guidance on the ethics, culture, environmental, and sustainable transformation of rural landscape systems, at all scales, and from international to local administrative levels. Acknowledging the global importance of culturally-based food production and use of renewable natural resources, and the issues and threats challenging such activities within contemporary cultural, environmental, economic, social, and legal contexts.' (ICOMOS 2017a)

The document, as is the case with all documents of this type, international or regional, which preceded it, constitutes a reference point either general or in part concerning its cultural significance. It thus becomes useful as information on the 'state of the art' in document format.

The Principles text, therefore, is an addition to global documents concerning historical and cultural heritage: such as the Venice Charter (ICOMOS 1964), the UNESCO World Heritage Convention (UNESCO 1972), the Nara Document on Authenticity (ICOMOS 1994), and the Burra Charter (Australia ICOMOS 2013), expanding and integrating fields of interest.

\section{The Principles Document}

The 'Principles Concerning Rural Landscapes as Heritage' (ICOMOS 2017) is split into two sections. The first, ('I. Principles') is specific to the subject of interest, indicating its values ('I.A. Definitions; I.B. Importance'), but also the current risks and critical aspects to which the heritage related to rural landscapes is subject. It also considers the potential, opportunities and benefits that rural landscapes can bring in terms of a place's sustainability ('C. Threats, D. Challenges, E. Benefits, F. Sustainability'). The second section ('II. Action Criteria') provides principles and criteria for the protection and promotion of heritage related to rural landscapes. It is divided into chapters concerning the steps to be taken: knowledge, protection, sustainable management, communication and transmission of physical places and the values associated with them ('Specific measures are: understand, protect, sustainably manage transformation, communicate and transmit landscapes and their heritage values') (ICOMOS 2017a).

\section{Section I: Definitions and Values}

The first section defines the main theoretical questions through two concepts ('rural landscape', and 'rural landscape as heritage'): these are fundamental in understanding the entire document. The first definition ('rural landscape') is packed with content and implications. The 
concept of 'rural landscape' signifies all areas resulting from the interaction of humans and nature to produce food and other renewable resources useful to humankind: ‘... rural landscapes are terrestrial and aquatic areas coproduced by human-nature interaction used for the production of food and other renewable natural resources' (ICOMOS 2017a).

The section then presents a general ranking of points of interest, covering all parts of the globe with the intent of giving valid meaning across cultures to the areas resulting from the interaction of man and nature '.. via agriculture, animal husbandry and pastoralism, fishing and aquaculture, forestry, wild food gathering, hunting, and extraction of other resources, such as salt' (ICOMOS 2017a).

There is an implicit distinction between 'rural' and 'agricultural': agricultural activity (featuring the term 'agriculture') is an activity historically focused on sedentary food production, and takes into account scientific debates and terminology which have enlivened historical, geographical and agronomic studies on the question of agriculture and rurality which continue to this day. The term 'rural', in the context of the Principles, is necessary to clearly articulate the types of production activities developed through the centuries in the various areas of the world, on top of that of simple agriculture. It acts as a kind of 'umbrella' definition inside which concepts like aquaculture and fishing, different kinds of animal husbandry, forestry management, hunting, natural product harvesting, extraction and working of shared resources such as salt, are collected, clarified and categorised.

In various parts of the world, each one of these activities has given rise to specific landscapes and continues to do so (e.g. saltworks, fishing valleys, and pasture lands). In other cases inter-connected agriculture has spread (think of the many examples of aquaculture for fish production in the rice fields of Asiatic regions as well as in Europe, a good example being areas on the Po river plain).

The first definition also introduces the concept of landscape and specifies the meaning given to it in the document. Such precision is necessary due to the changes undergone by the word's meaning during the $20^{\text {th }}$ century, moving from a concept of view and panorama based on aesthetic values, to the more complex definition now attributed, which has come to the fore over recent decades and has laid the foundations for international documents and treaties.

In the Principles, landscape is understood as the copresence of physical features ('rural landscapes are 'areas") and of meanings attributed to it ('rural areas have 'cultural meanings"): 'At the same time, all rural areas have cultural meanings attributed to them by people and communities.' (ICOMOS 2017a) The logical consequence is that 'all rural areas are landscapes'. In other words, rural activity creates rural spaces which can be read through the lens of landscape concepts, underlining both the physical characteristics and the multiple cultural values attributed to them. Therefore, all rural areas are landscapes.

The field of interest of the Principles is vast ('terrestrial and aquatic areas') (ICOMOS 2017a). Rural landscapes read as heritage are omni-present without geographical distinction like distance from urban areas and size which can vary from large areas to fragmented sections ('They can be huge rural spaces, peri-urban areas as well as small spaces within built-up areas') (ICOMOS 2017a). Only densely built areas of a city are excluded together with zones with a clearly different function like mines, quarries and waste landfills. Further study and experience will help to formulate new criteria for or modifications to the Principles text (for example, the open question of the historical relationship between mines and forested areas as landscape), as has been requested by the decree from the ICOMOS General Assembly in Delhi 2017 which adopted the Principles as a doctrinal text.

In the study of 'rural landscape as heritage', the current state of conservation must never influence their significance: there is equal interest in 'both well-managed or degraded or abandoned areas that can be reused or reclaimed' (ICOMOS 2017a). It is clear, however, there must always be a distinction between the knowledge of a place (for this reason, degraded or abandoned sites can be considered as rich with heritage value as well-preserved areas) and the evaluation of the heritage values. The two aspects are separate, even if they are inevitably connected in terms of the decision-making process that will lead to action being taken.

The field of interest is intentionally wide reaching, bringing with it the awareness that all rural areas have been subject to a long history of human-made transformation and use leaving clear, albeit sometimes difficult to recognise, traces to this day (for details see the following definition 'rural landscape as heritage').

The second definition from the Principles-'rural landscapes as heritage'-defines the concept of heritage in conjunction with the concept of landscape. The text defines how heritage can be present in rural landscapes and should be subject to study and eventual protection. Different types of heritage will be grouped into two macro areas in terms of tangible heritage ('physical attributes' 
like 'morphology', 'vegetation', 'settlements', and 'hydrography') and 'intangible' heritage (knowledge, social structures, practices, cultural, spiritual and natural attributes). These are well known to those studying historical heritage. They make up the basis of the knowledge required to characterise a rural area, also known as 'biocultural diversity' and form one of its fundamental corner-stones.

The Principles confirms that heritage values can be present in all rural areas: 'All rural areas can be read as heritage, both outstanding and ordinary, traditional and recently transformed by modernisation activities' while, depending on the location, 'heritage can be present in different types and degrees' (ICOMOS 2017a).

The Principles do not address questions of evaluation, which would require specific scientific investigation (Calabrò 1981). This could be successively carried out by the WRLI. Value derives from changes in epoch and events taking place over the history of man-nature interaction: historical traces can be seen in the present, like a palimpsest ('related to many historic periods, as a palimpsest') (Corboz 1983). Studies into history, geography, environmental and landscape archeology, ecology, as well as anthropology, art history and semiology, are fundamental cultural references (Bloch 1952; Sereni 1961; Gambi 1972; Rackham 1980; Cosgrove 1984; Schama 1997; Emanuelsson 2009). These are not only relevant to clear signs of human intervention (e.g., buildings, pasture lands, and fields) but also the less evident traces of human civilisation and transformation of nature. Both situations are tricky in their reading as they require consideration in quantitative and qualitative terms of the traces-both material and immaterial-visible in the present day.

The concepts expressed in the Principles in the two definitions represent a strongly innovative declaration when compared with the traditional political vision of protection of heritage that has lost efficacy, and which is based on a reading of heritage as specific areas to be chosen and protected for their exceptional qualities. In particular, there is a common over-simplification that tries to split rural areas into two categories: the first is related to industrialised production, having lost any historical memory or heritage value, the second is related to areas where any remaining traditional activity is viewed as an oasis of cherished values at risk of disappearing forever. This type of prejudice really distinguishes extremes of black and white, ignoring the many shades of 'colour' that exist in between if we are willing to search them out.

Other points in section I of the Principles ('B. Importance, C. Threats, D. Challenges, E. Benefits') briefly develop themes on the reasons for the importance of rural landscapes and their benefits from a cultural heritage point of view for today's society, not forgetting the threats of their destruction and the challenges that must be faced to examine the situation from a different perspective. This is one of the most studied and well-known material by scholars, scientific and cultural associations and public administrations, both at international and local levels.

Two declarations, contained in section I, sum up the main concepts that form the basis of detailed protection policy which are then further developed in section II. The first concerns the recognition of rural landscapes as a resource, considering their heritage value: 'Rural landscapes are multifunctional resources.' In other words, rural landscapes are not only a productive, social and economic resource, as is well recognised, but have a socio-cultural value as well, constituting an added, strategic character. This will interact with other resources and increase the overall potential of such places to make them sustainable not only for local populations but all society.

The second declaration concerns the creation of policy that will interpret, protect, enhance and correctly use the values of heritage, while recognising the inevitable transformations always characterising rural landscapes: 'rural landscape policies should focus on managing acceptable and appropriate changes over time, dealing with conserving, respecting, and enhancing heritage values' (ICOMOS 2017a). The ability to manage time is essential.

\section{Section II: Action Criteria}

Section II focuses on the fundamental criteria that will inspire courses of action. These will be complementary and will be defined with awareness of: knowledge (II.A Understand rural landscapes and their heritage values), protection (II.B Protect rural landscapes and their heritage values), sustainable transformation (II.C. Sustainably manage rural landscapes and their heritage values) and communication and public awareness (II. D. Communicate and transmit the heritage and values of rural landscapes). Certain transversal points within the Principles are useful to clarify the main cultural premises and contents of the document.

\section{The Importance of Time in Policy Strategy}

Time is strategic in heritage policy choice for rural landscapes. The document focuses on the process of designing and programming both daily and one-off operations at all levels: 'II.B.5. Prepare effective policies based on informed local and other knowledge of the landscapes, 
their strengths and weaknesses, as well as potential threats and opportunities. Define objectives and tools. Program actions with regard to long, medium, and shortterm management goals' (ICOMOS 2017a). Such an approach is stipulated by international documentation, in particular, the European Landscape Convention (Council of Europe 2000) Art. 6 and its Guidelines (Council of Europe 2008), but also the Guidelines for Management Plans of sites of the World Heritage List (ICOMOS 2010). The approach is laid out and tested by international operational research and through collaboration between regional and local public administration (e.g. in Europe the international projects L.O.T.O. and PaysMED ${ }^{2}$ ). The key points for effective decision-making processes are: the detailed and deep knowledge of each landscape and its tangible and intangible characteristics; strengths, risks, potential and opportunity analysis (the well-known SWOT analysis); and defining landscape quality objectives specific to each place that identify strategies and actions to reach such objectives.

Establishing goals must not only be an issue of rural landscape heritage protection and enhancement, but rather a holistic approach aimed at 'sustainable' landscape quality in the aspects of the current concept of sustainability. This integrates the original three pillars (economy, environment and society) with a fourth pillar of culture as this is a complementary resource.

Possible actions are 'conservation, repair, innovation, adaptive transformation, maintenance, and long term management'. As with every landscape, one site may require all these types of actions at the same time but in differing measures, independently of recognised values (exceptional or ordinary), conservation status and geographical and administrative scale ('Define strategies and actions of dynamic conservation, repair, innovation, adaptive transformation, maintenance, and long term management') (ICOMOS 2017a, Section B.5.). Insistence on the concept of management, present in many sections of the Principles, underlines the fact that rural landscapesalong with all landscapes, in fact-are subject to continuous, inevitable and irreversible transformation. Effective strategies that correctly consider heritage value will manage these transformations.

Tools that lead to policy include 'laws, rules, economic strategies, governance solutions, information sharing, and cultural support' (ICOMOS 2017a, Section II.B.2.), as well as landscape and territorial planning and design. Thus, it is necessary to have cross-sector rural landscape policies, as should be the case in any effective landscape strategy, that give a new integration of different policies and tools (e.g., agriculture, energy, ecology, culture, tourism, urban planning, economy, and society).

\section{The (False) Contradiction of Conservation and In- novation: 'Appropriate' Transformation}

The document introduces the concept of 'dynamic conservation' ('II.B.3 Define strategies and actions of dynamic conservation...') to underline the fact that conservation of rural landscapes - as ongoing landscapes-must be understood in its own right.

Over the history of cultural heritage protection, especially for buildings, conservation is often seen as a desire to stop-even 'freeze' - the site to avoid further detrimental change, especially physical change. Critics have spoken of the 'muzzling' of sites, wanting to keep them as museums with artifacts or traditional techniques or ways of life to be guarded, understood by few and touched by even fewer (as in the origin of museums). Such an attitude has often led to conflict, above all, in the management of the lives of local populations. Such a radical interpretation of conservation, already theoretically difficult when concerning buildings and other heritage, is even less applicable in the case of ongoing landscapes and rural landscapes, as they are subject to continuous human energy-both individuals and the community as a whole-and to cycles of nature and environmental change, rules and opportunities for production of food, as well as economic, social, cultural, local and global impulses.

The concept of dynamic conservation implies the centrality of the time perspective-short, medium and long term-in the choices made and actions undertaken and the awareness of the importance of management of small but daily transformations (daily management): 'As landscapes undergo continuous, irreversible, and inevitable processes of transformation, rural landscape policies should focus on managing acceptable and appropriate changes over time, dealing with conserving, respecting, and enhancing heritage values.' (ICOMOS 2017a)

The concept of dynamic conservation is strictly linked to the need to reflect on the question and methodology of the transformation. Recognition of a place's intrinsic dynamism does not mean allowing simply any change to take place, especially when based on sectoral or partial needs, rather, it means basing choices on knowledge and respect for a place and its inherited character. This is a pre-condition before making any other choices of transformation.

The concept of 'respecting' inherited values and implied character requires awareness of the need to set limits 
and quality criteria for transformation ('acceptable and appropriate changes over time') (Roca, Claval, and Agnew 2011; Scazzosi 2011). There can be no destruction without awareness of values we destroy, even in inevitable transformation. Transformative sustainability is the goal as a future strategy.

This also, means continuity. Transformation inevitability and irreversibility as a concrete and positive way to manage rural landscape quality using and enhancing heritage values involves conscious future construction, not nostalgia for a past that will not return. This is, in some ways, turning the received wisdom of heritage management on its head: the central point becomes the relationship between innovation and conservation in historical feature transformation management. This has been the subject of theoretical and practical study of historical heritage (artefacts, monuments, single buildings, historical cities and gardens, modern architecture) as can be clearly seen in the history of heritage management. It has been at the centre of recent debate and international documents concerning historical cities as the UNESCO Recommendation on the Historic Urban Landscape (UNESCO, 2011).

The concept of dynamic conservation does not, however, mean ignoring the heritage value of rural landscapes. It is clear there must be a distinction between the requalification of neglected and degraded areas and those using innovation to seek new functionality. It is essential that each of us is aware of the heritage character present in a rural landscape. It must also be clear that the individual characteristics of a place must also determine its weighting and role.

Landscape needs an interwoven fabric of protection, innovation and re-qualification. In a single area (whether that be an area of particular quality or completely normal, or to be re-qualified or innovated) certain aspects must be protected, other aspects reorganised, others again requalified and still others innovated ('Define strategies and actions of dynamic conservation, repair, innovation, adaptive transformation, maintenance') (ICOMOS 2017a, Section II.B.3.).

The Principles always require a reading of heritage values in every transformative operation, recognizing that the artificial nature of rural landscape will always produce some of these values, even where these may be hidden or faintly visible or not well conserved at all, because these are resources they possess. Here, limits must be assessed beyond which rural landscapes will be destroyed either in a physical way or in significance or used as a purely instrumental asset. The references in the Principles text to the European Landscape Convention 2000 (Council of Europe 2008), UNESCO orientations for Cultural Landscapes in WHL (Mitchell, Rössler and Tricaud 2009) and recent general views (Roe and Taylor 2014) are clear.

\section{The Role of the Stakeholders}

A second concept is present throughout the Principles text: this concerns the governance of rural landscape and the role of stakeholders, whether they be individuals, organised groups, associations, communities or public or private bodies.

The document develops a cultural guideline of global operation concerning rural landscapes and the participation within these of populations - not only local onesin the process of cultural heritage recognition, policy and strategy governance and daily management.

This is the subject of a growing number of international documents, such as the Convention for the Safeguarding of Intangible Cultural Heritage (UNESCO, 2003b), the Recommendations for Historical Urban Landscape (UNESCO, 2011) and debates, e.g. the theme of the General Assembly at ICOMOS 2017 was 'Heritage and Democracy' (ICOMOS 2017b). It is the focus of general documents on landscape, especially the European Landscape Convention (Council of Europe 2000), and on heritage as the Faro Convention on the Value of Cultural Heritage for Society (Council of Europe 2005). The idea is that knowledge and use of heritage forms part of the citizen's right to participate in cultural life as defined in the Universal Declaration of Human Rights.

The Principles confirm the importance of active participation from all stakeholders and hope for a support role to be played by public administration: 'Consider that effective policy implementation is dependent on an informed and engaged public, on their support for required strategies and involvement on actions. It is essential to complement all other actions. Public administrations should support pro-active and bottom-up initiatives' (ICOMOS 2017a, Section II.B.7.) In the case of rural landscapes, the reasons are even stronger than for other heritage areas: rural landscapes are a centuries old tradition in whose upkeep all have a role and responsibility, individually or collectively. Stakeholders are not only the administrators, business community and corporations, but all those in daily contact with such sites, imperceptibly modifying them, like farmers above all in rural areas and citizens in the urban fabric of metropolitan areas.

Farmers have a key role to play: they are responsible for the production of a population's source of sustenance; 
they are passers-on of knowledge, having, in many cases, contributed to shaping and conserving rural landscape to this day; they are the maintainers and guardians of their territory. The farming community has also the historical memory of tradition which would otherwise quickly disappear with the shift of population from rural areas to big cities. We must 'Recognise key stakeholders of rural landscapes, including rural inhabitants, and the local, indigenous, and migrant communities with connections and attachments to places, their role in shaping and maintaining the landscape, as well as their knowledge of natural and environmental conditions, past and present events, local cultures and traditions, and scientific and technical solutions trialed and implemented over the centuries.' (ICOMOS 2017a, Section II.C.2) The Principles underline the highly important role of local, indigenous or migrant populations in the conservation of the relationship between humans and nature, a role that in many areas of the world can be of paramount importance as more recent generations have begun to shun such inherited knowledge.

Attention to the quality of life of rural workers is fundamental for effective policy for rural landscapes, as is recognition and respect for their professional status: a principle stemming from a positive change in consideration of the role of food production in many areas of the world which are increasingly at risk of starvation and drought ('Acknowledge that the good standard and quality of living for rural inhabitants enables strengthening of rural activities, rural landscapes, and transmission and continuity of rural practices and cultures') (ICOMOS 2017a Section II.C.2).

There is a need to stop rural decline, the flight of population from rural areas and find solutions to 'needs of rural workers' quality of living, which is a prerequisite for the continuation of activities that generate and sustain rural landscapes. Such necessities are now of a widespread nature and not only limited to economic aspects: 'Quality of living consists of both income and social appreciation, provision of public services including education, recognition of culture rights, etc.' ('Find a balance') (ICOMOS 2017a, Section II.C.5)

In the present-day relationship between urban and countryside dwelling, it is the large metropolitan areas which are experiencing growth across all continents. Within this phenomenon, urban dwellers and farmers are the key players and are often linked through forms of urban farming, a widespread trend but one which has only recently been specifically and systematically studied (Lohrberg, Licka, Scazzosi and Timpe 2016). Residents require multi-functionality from their rural landscape, which is a resource on many levels for their quality of life: 'recreation, food quality and quantity, firewood, water and clean air quality, food gardening' as well as 'ecosystem services. They can be considered also as a new form of urban parks. In turn, farming activity can benefit from proximity to cities, where production can be integrated with other economically relevant operations ('recreation, education, agri-tourism, etc.), in a process known as 'multi-functionality' (ICOMOS 2017a, Section II.C.4). In such cases, rural landscape heritage is a resource in terms of local identity, site and local residents' quality of life, quality of food (for example, in the short chain), as well as environmental knowledge, agricultural culture and techniques and oral memory.

All stakeholders must be fundamentally engaged in the process of knowledge, decision making and management: 'Consider that effective policy implementation is dependent on an informed and engaged public, on their support for required strategies and involvement on actions. It is essential to complement all other actions.' (ICOMOS 2017a, Section II.B.7) Public administration is key because it promotes and supports pro-active events and participation. The bottom up approach can find its place, complementing top down approaches, in public administration at various levels. Theoretical, methodological and experimental participation has been studied in many parts of the world to find tools and ways that guarantee efficacy but, at the same time, keep the competencies, roles and responsibility of public and private players specific and clear. Many international projects are experimenting with this, such as the recent European $\mathrm{REACH}^{3}$.

\section{Value Recognition: Knowledge, Information, Communication and Public Reception}

The Principles dedicate a specific section to the knowledge process and the areas of information, communication and public reception. These are all fundamentals in a strategic approach that understands the importance of widespread participation by the population in the management of heritage site character, where all players share a long-term view.

The Principles consider the question in two sections, one focusing on knowledge entitled 'Understand Rural Landscapes and Their Heritage Values' (ICOMOS 2017a, Section II.A.) and one on value communication entitled 'Communicate and Transmit the Heritage and Values of Rural Landscapes' (ICOMOS 2017a, Section II.D), creating criteria and suggesting methods and tools.

Knowledge has to be gained before any kind of actions (conservation, innovation or requalification): it is the basis 
for all planning, design, protection, management and monitoring tools, but also for informing and raising public awareness and training for technicians. As indicated in the definitions developed in Section I of the text entitled 'Rural Landscape and Heritage', knowledge must be ever present in all rural landscape assessment ('Recognise that all rural landscapes have heritage values, whether assessed to be of outstanding or ordinary values') (ICOMOS 2017a, Section II.A.1), both in terms of physical characteristics as well as tangible and intangible values.

As with every landscape, knowledge content should concern the current physical site characteristics; sociocultural perception; inherited and contemporary history; present day changes taking place concerning physical and cultural aspects; and ongoing dynamics and the challenges they pose. In the case of rural landscapes, historical knowledge also requires an understanding of spatial, functional, productive, cultural and social relationships which have led them to become 'production systems' and which can still be read to this day. The Principles recognise that knowledge of value is key ('such heritage values will vary with scale and character, shapes, materials, uses and functions, time periods, changes') (ICOMOS 2017a), but do not look at assessment difficulties, which would require rural landscape specific methodological investigation.

Tools like inventories, catalogues and mapping allow for systematic knowledge of scale ('world, regional, national, local') and, at the same time, are specific to each place: these are tools already widely used in all other areas of heritage management, from buildings and historical cities to gardens. However, for a complex subject like rural landscapes, experience is often limited and incomplete, methodology is not shared, tested or consolidated and results are difficult to compare, above all, when seen at large scales. This is especially true when considering all rural landscapes not only sites classified as exceptional.

Large scale description is often boiled down to analysis of maps and land use or geographical description/historical anecdotes with a list and mapping of a site's make up (e.g., buildings, channels, lines of trees, agriculture, and agricultural techniques). Comparison is difficult where sites have similarities (e.g. terraced landscapes, vine plantations, and places with studied history thanks, in part, to being candidates on the World Heritage List).

The Rural Landscape Atlas project by ICOMOS-IFLA ISCCL is working towards methodological criteria for a unified and systematic approach to reading rural landscape at all levels. It puts forward a first classification level concerning macro-categories (clear physical or historical characteristics and comparative research on landscape on the World Heritage List). This includes a description of historical characteristics that maps organisation, function, production, social, economic and cultural relevance giving rise to characteristics partly or completely visible todaylandscape as physical expression of production function, social organisation and cultural value, a kind of great production 'machine' (Lebeau 1969; Tricot 2013; Scazzosi 2018; Laviscio 2018).

Knowledge production comes through integration of competencies from experts, ordinary citizens (not only those who are local) and stakeholders ('integrate local, traditional and scientific knowledge') (ICOMOS 2017a, II.A. 4), in an interdisciplinary relationship (contribution from various fields) and is, itself, inter-disciplinary, with a reciprocal exchange and integration across all stakeholders-citizens, farmers, technicians, experts and owners ('Recognise local populations as knowledge-holders') (ICOMOS 2017a, Section II.A.6). In this framework, ease of data availability, reading and understanding is key both for specialists and non-specialists with organised data return systems. It is also necessary to have feasibility studies of the costs of inventory, catalogues and mapping. Other necessary elements of any inventorying and cataloguing project include the time necessary for data collection and difficulty in its processing, expert presence, nonexpert involvement methods, investigative organisation (one superficial but geographically relevant, others going into further depth) and database comparison at different administrative levels. Experience gathered for other types of heritage is also paramount.

Testing and reflection on positive and problematic results of involving local populations are underway in many countries around the world, covering a huge variety of traditional and cultural diversity. These show the efficacy of tools, approaches and communication practices based on best practice, guidelines, operational (e.g. help and technical desks) technical and professional training; educational programs in schools, training courses in universities; award ceremonies and widespread use of media ('Communicate awareness of the heritage values of rural landscapes through collaborative participatory actions, such as shared learning, education, capacity building, heritage interpretation and research activities') (ICOMOS 2017a, Section II.D.1).

The role of technicians and experts (landscapers, planners, historians, geographers, botanists, naturalists and conservationists) changes and requires interaction, understanding and mediation, while recognising the differing roles, competencies and responsibilities each group has. 


\section{Conclusions}

The Principles Concerning Rural Landscapes as Heritage and the World Rural Landscapes Initiative aims to not only recognise the importance of rural landscapes, but also to support the development of conservation and management policies that can be applied to them. It intends to be an opportunity for a further analysis and debate among experts and stakeholders, who-at various levels-have to do with rural landscapes as historical and cultural heritage, and who participate in the definition of policies.

The WRLI started from the lack of theory and methodological difficulties of UNESCO elaboration. It aims to support scientific identification, description, comparison and evaluation during studies for site candidature on the UNESCO World Heritage List and related policies. The goal is to enhance the 'continuing cultural landscapes' category, sub-category 'ongoing landscapes'.

At the same time, WRLI will support the actions of administrations, farmers and people at all levels (national, regional, local) whenever they are conscious of the importance of heritage aspects of rural landscapes and are involved in its protection and use.

The general goal is to clarify that rural heritage is both a resource for human development, the enhancement of cultural diversity and the promotion of intercultural dialogue, and part of an economic development model based on the principles of sustainable resource use.

The Principles text, as with all universal texts, is not intended to be absolute and able to cover all questions and specificities of all places of the world. In addition, it is time-specific and, in the future, it should be subject to review, revisions, additions and up-dating, in connection with the on-going transformation of the concepts and approaches to heritage.

\section{Notes}

1. www.worldrurallandscapes.org

2. www.paysmed.net

3. www.reach-culture.eu

\section{References}

Agnoletti, Mauro, ed. 2013. Italian Historical Rural Landscapes. London-New York: Springer.

Australia ICOMOS. The Burra Charter. The Australia ICOMOS Charter for Places of Cultural Significance. Accessed 18 September 2018. https://australia.icomos.org/
wp-content/uploads/The-Burra-Charter-2013-Adopted-31.10.2013.pdf

Bloch, Marc. 1952. Les Caractères originaux de l'histoire rurale française [The Original Characters of French Rural History] Paris : Librairie Armand Colin.

Brandi, Cesare. 1963. Teoria del restauro [Restoration Theory] Turin: Einaudi.

Cameron, Christina, and Mechtild Rössler, eds. 2013. Many Voices, One Vision: The Early Years of the World Heritage Convention. Aldershot: Ashgate.

Calabrò, G. 1981. Issue: "Valori." In Enciclopedia Einaudi Vol. 14, edited by Ruggieno Romano. 935-961. Torino: Einaudi.

Choay, Françoise. 1992. L'Allegorie du patrimoine [The Allegory of Heritage]. Paris: Seuil.

Cleere, Henry. 1995. "The Evaluation of Cultural Landscapes: the Role of ICOMOS." In Cultural Landscapes of Universal Values: Components of a Global Strategy, edited by Bernd von Droste, Harald Plachter, and Mechtild Rössler, 50-59. New York: Fischer.

Corboz, André. 1985. "Il territorio come palinsesto." Casabella 516: 22-27.

Cosgrove, Denis. 1984. Social Formation and Symbolic Landscape. Madison: University of Wisconsin Press.

Council of Europe. 2000. European Landscape Convention. Accessed 18 September 2018. https://rm.coe.int/CoERMPublicCommonSearchServices/DisplayDCTMCon tent?documentId=0900001680080621

Council of Europe. 2008. Guidelines for the Implementation of the European Landscape Convention. Accessed 18 September 2018. https://rm.coe.int/CoERMPublicCommonSearchServices/DisplayDCTMContent?documentI $\mathrm{d}=09000016802 \mathrm{f} 80 \mathrm{c} 9$

D’Angelo, Paolo. 2001. Estetica della natura. Bellezza naturale, paesaggio, arte ambientale [Aesthetics of Nature. Natural Beauty, Landscape, Environmental Art]. Bari : Laterza.

Deléage, Jean-Paul. 1991. Histoire de l'Ecologie [History of Ecology]. Paris : La Découverte.

Donadieu, Pierre, Hansjörg Küster, and Raffaele Milani. 2008. La cultura del paesaggio in Europa tra storia, arte e pratica [Landscape Culture in Europe between History, Art and Practice]. Firenze: Olschki.

Droste, Brend, Plachter Harald, and Mechtild, Rössler, eds. 1995. Cultural Landscapes of Universal Value: Components of a Global Strategy. New York: Fischer.

Emanuelsson, Urban. 2009. The Rural Landscapes of Europe: How Man Has Shaped European Nature. Stockholm: Formas. 
Fairclough, Graham, and P. G. Møller, eds. 2008. Landscape as Heritage. Berne: Geographica Bernensia.

Fowler, Peter, ed. 2003a. "World Heritage Cultural Landscapes 1992-2002." World Heritage Papers 6. Paris: UNESCO.

Fowler, Peter. 2003b. "World Heritage Cultural Landscapes 1992-2002: A Review and Prospect.” World Heritage Papers 7. Paris: UNESCO.

Gambi, Lucio. 1972. "I valori storici dei quadri ambientali." In Storia d'Italia Vol. I, 5-60. Torino: Einaudi.

Gfeller, Aurélie, Elisa. 2013. "Negotiating the Meaning of Global Heritage: 'Cultural Landscape' in the UNESCO World Heritage Convention, 1972-92." Journal of Global History 8: 483-503.

Goetcheus, Cari, and Nora Mitchell. 2014. "The Venice Charter and Cultural Landscapes: Evolution of Heritage Concepts and Conservation over Time." Change Over Time 12 (2): 338-357.

Han, Feng. 2012. "Cultural Landscape: A Chinese Way of Seeing Nature." In Managing Cultural Landscapes, edited by Ken Taylor and Lennon Jane, 90-108. London: Routledge.

ICOMOS. 1964. International Charter for the Conservation and Restoration of Monuments and Sites (The Venice Charter 1964). Accessed 18 September 2018. https:// www.icomos.org/charters/venice_e.pdf

ICOMOS. 1982. Charter of Historic Gardens (The Florence Charter) Accessed 18 September 2018. https://www. icomos.org/charters/gardens_e.pdf

ICOMOS. 2010. "Management Plans and the World Heritage Convention: A Bibliography." Accessed 23 February 2018. www.icomos.org/centre_documentation/bib/ Management_plans_bibliography.pdf

ICOMOS. 2017a. "ICOMOS-IFLA Principles Concerning Rural Landscapes as Heritage". Accessed 14 September 2018. https://www.icomos.org/images/DOCUMENTS/ Charters/GA2017_6-3-1_RuralLandscapesPrinciples_ EN_adopted-15122017.pdf

ICOMOS. 2017b. The Delhi Declaration on Heritage and Democracy.

Jokilehto, Jukka. 1999. A History of Architectural Conservation. Oxford: Butterwhort-Heinemann.

Laviscio, Raffaella. 2018. "Knowledge of Rural Landscape Systems: an International Proposal for a Classification.” In The Conservation and Enhancement of Built and Landscape Heritage, edited by Elisabetta Rosina and Lionella Scazzosi, 55-66. Milano: Poliscript.

Leach Edmund. 1980. "Natura/Cultura." In Enciclopedia Einaudi, Vol. 9, edited by Ruggieno Romano, 757-791.
Torino: Einaudi.

Le Goff, J. 1978. “Documento/Monumento.” In Enciclopedia Einaudi, Vol. 5, edited by Ruggieno Romano, 38-48. Torino: Einaudi.

Lennon, Jane. 2012. "Cultural Landscape Management: International Influences." In Managing Cultural Landscapes, edited by Ken Taylor and Jane Lennon, 45-69. Abington: Routledge.

Lebeau, R. 1969. Les grands types de structure agraire dans le monde [The Main Types of Agrarian Structure in the World]. Paris: Éd Masson.

Lohrberg, Frank, Lilli Licka, Lionella Scazzosi, and Axel Timpe, eds. 2016. Urban Agriculture Europe. Berlin: Jovis.

Luginbühl, Yves. 2012. La mise en scène du monde: Construction du paysage européen [The Staging of the World. Construction of the European Landscape]. Paris: CRNS Editions.

Meeus, J. H. A., M.P. Wijermans, and M.J. Vroom. 1990. "Agricultural Landscapes in Europe and their Transformation." Landscape and Urban Planning 18: 289-352.

Mitchell, Nora, Mechtild Rössler, and Pierre-Marie Tricaud. 2009. "World Heritage Cultural Landscapes. A Handbook for Conservation and Management." World Heritage Papers 26. Paris: UNESCO.

Olwig, Kenneth Robert. 2002. Landscape, Nature, and the Body Politic: From Britain's Renaissance to America's New World. Madison: University of Wisconsin Press.

Pungetti, G., and A. Kruse, eds. 2010. EUCALAND. European Culture Expressed in Agricultural Landscapes. Perspectives from the Eucaland Project. Rome: Palombi.

Rackham, Oliver. 1980. Ancient Woodland: Its History, Vegetation and Uses in England. London: Eduard Arnolf.

Roca, Zoran, Paul Claval, and John Agnew, eds. 2011. Landscapes, Identities and Development. Abington: Routledge.

Roe, Maggie, and Ken Taylor, eds. 2014. New Cultural Landscapes. Abington: Routledge.

Scazzosi, Lionella. 1993. Il giardino opera aperta: la conservazione delle architetture vegetali [The Garden Operates Open: Conservation of Plant Architecture]. Florence: Alinea.

Scazzosi, Lionella, eds. 1999. Politiche e culture del paesaggio: Esperienze internazionali a confronto [Landscape Policies and Culture: A Comparison of International Experiences]. Roma: Gangemi.

Scazzosi, Lionella, ed. 2002. Leggere il paesaggio: Confronti internazionali [Reading the Landscape: International Comparisons]. Roma: Gangemi.

Scazzosi, Lionella. 2003. "Landscape and Cultural 
Landscape: European Landscape Convention and Unesco Policy." In Cultural Landscapes: The Challenges of Conservation UNESCO World Heritage Papers 7 , 55-59. Paris: UNESCO.

Scazzosi, Lionella. 2004. "Reading and Assessing the Landscape as Cultural and Historical Heritage." Landscape Research 29 (4): 335-355.

Scazzosi, Lionella. 2011. "Limits to Transformation in Places Identity. Theoretical and Methodological Questions." In Landscape, Identity, Development, edited by Z. Roca, P. Claval, and J. Agnew, 9-24. Farhnam: Ashgate. Scazzosi, Lionella. 2018. "Landscape as System of Tangible and Intangible Relationships. Small Theoretical and Methodological Introduction to Read and Evaluate Rural Landscape as Heritage." In The Conservation and Enhancement of Built and Landscape Heritage, edited by E. Rosina and L. Scazzosi, 19-40. Milano: Poliscript. Accessed 18 September 2018. https://re.public. polimi.it/retrieve/handle/11311/1050122/275347/Pubblicazione\%20Mondonico_290318_DEF-compressed. pdf

Sereni, Emilio. 1961. Storia del paesaggio agrario italiano [History of the Italian Agricultural Landscape]. Bari: Laterza.

Schama, Simon. 1995. Landscape and Memory. London: Harper Collins.

Taylor, Ken, and Jane Lennon, eds. 2012. Managing Cultural Landscapes. Abington: Routledge.

Taylor, Ken. 2012. "Landscape and Meaning: Context for a Global Discourse on Cultural Landscape Values." In Managing Cultural Landscapes, edited by Ken Taylor and Jane Lennon, 21-44. London: Routledge.

Taylor, Ken, and Kevin Francis. 2014. "Culture-nature Dilemmas: Confronting the Challenge of the Integration of Culture and Nature." In New Cultural Landscapes, edited by Maggie Roe and Ken Taylor, 41-58. Abington: Routledge.

Tricaud, Pierre-Marie. 2013. "Agricultural Landscapes in a World Heritage Context." World Heritage 69.

UNESCO. 1972. Convention Concerning the Protection of the World Cultural and Natural Heritage. Accessed 18 September 2018. http://whc.unesco.org/en/conventiontext/

UNESCO. 1995. Asian Rice Culture and Its Terraced Landscapes. Report on the Regional Thematic Study Meeting Manila (Philippines), 28 March to 4 April 1995. Accessed 18 September 2018. http://whc.unesco.org/en/ events/1111/

UNESCO, ed. 2003a. Cultural Landscapes: the Challenges of Conservation, Proceedings of the Workshop, Ferrara 11-12 November 2002. UNESCO World Heritage Papers 7. Paris: UNESCO.

UNESCO. 2003b. Convention for the Safeguarding of the Intangible Cultural Heritage. Accessed 18 September 2018 https://ich.unesco.org/en/convention

UNESCO. 2011. Recommendation on the Historic Urban Landscape. Accessed 18 September 2018. http://whc. unesco.org/uploads/activities/documents/activity-638-98.pdf 